\title{
“QUEM VIVE DE PRESENTE É O MUSEU”: A DINÂMICA DO MEMORIAL DO COLÉGIO FARROUPILHA DE PORTO ALEGRE/RS
}

\author{
Alice Rigoni Jacques ${ }^{1}$ \\ PontifíciaUniversidade Católica do Rio Grande do Sul \\ alice_rigoni@hotmail.com \\ Gabriela Mathias de Castro ${ }^{2}$ \\ Pontifícia Universidade Católica do Rio Grande do Sul \\ gabrielaortsac@gmail.com
}

\begin{abstract}
RESUMO
O artigo analisa o Memorial do Colégio Farroupilha, um museu escolar, localizado no Colégio Farroupilha em Porto Alegre/RS, criado em 2002, com o objetivo de salvaguardar o patrimônio histórico-escolar da instituição e de sua mantenedora - a Associação Beneficente Educacional (ABE - 1858), fundada por imigrantes alemães há mais de 150 anos. O acervo do Memorial é composto por uniformes, cadernos, fotografias, entre outros tantos documentos. Este estudo procura apresentar a dinâmica do Memorial, entre documentos e atividades, visando descontruir a ideia de que o museu é um local estagnado, reduto de coleções, dispostas apenas à contemplação. Abordaremos as investigações históricas suscitadas a partir da problematização do acervo, bem como as atividades didáticas e de pesquisas realizadas no espaço.
\end{abstract}

Palavras-chave: História da Educação. Patrimônio histórico-escolar. Memorial do Colégio Farroupilha.

\section{THOSE WHO LOVE IN THE PRESENT ARE MUSEUMS. THIS IS THE PROPOSAL OF THE FARROUPILHA SCHOOL}

\begin{abstract}
This article analyzes the Farroupilha School Memorial, an educational museum, which is located in Porto Alegre, at Farroupilha School. It was created in 2002 with the purpose of preserving the educational-historic patrimony of this Institution and its sponsor. Ir was founded by german imigrants about 150 years ago. There are uniforms, notebooks, photos, among other documents in its collection. This study intends to present the dynamics of the Memorial, documents and activities, aiming the deconstructing of the idea that museums are standing places or stronghold collections, organized just to be appreciated. We are going to talk about historic studies which were raised based on the questioning of this heritage, as well as teaching activities and researches carried out in this space.
\end{abstract}

Keywords: The history of Education. Historic-Educational patrimony. Farroupilha School Memorial.

\footnotetext{
${ }^{1}$ Coordenadora do Memorial do Colégio Farroupilha/RS.

${ }^{2}$ Monitora do Memorial do Colégio Farroupilha.
} 


\section{“QUIEN VIVE DEL PRESENTE ES EL MUSEO”: LA DINÁMICA DEL MEMORIAL DEL COLEGIO FARROUPILHA DE PORTO ALEGRE/RS RESUMEN}

El artículo analiza el Memorial del Colegio Farroupilha, un Museo escolar, localizado en el Colegio Farroupilha en Porto Alegre/RS, fundado en 2002, con el objetivo de salvaguardar el patrimonio histórico-escolar de la institución y de su mantenedora - la Asociación Beneficiente Educacional ( $\mathrm{ABE}$ - 1858), fundada por inmigrantes alemanes a más de 150 años. La colección del Memorial está compuesta por uniformes, cuadernos, fotografías, entre tantos documentos. Este estudio busca presentar la dinámica del Memorial, entre documentos y actividades, con el objetivo de desconstruir la idea de que el museo es un sitio estanque, reducto de coleciones, dispuestas a penas para la contemplación. Discutiremos las investigaciones históricas a partir de la problematización de la colección, bien como las actividades didácticas y de investigación realizadas en el espacio.

Palabras claves: Historia de la Educación; Patrimonio histórico-escolar; Memorial del Colegio Farroupilha

\section{INTRODUÇÃO}

$\mathrm{O}$ arquivo é excesso de sentido quando aquele que o lê sente a beleza, o assombro e um certo abalo emocional. Esse lugar é secreto, diferente para cada um, porém, em todo itinerário ocorrem encontros que facilitam o acesso a ele e, sobretudo, à sua expressão (FARGE, 2009, p. 36).

Ao introduzirmos este estudo sobre o Memorial do Colégio Farroupilha, achamos por bem lançarmos um olhar para além de um lugar apenas de contemplação, mas como um espaço de matizes e tessituras sentimentais, carregado de beleza e significados que suscitam múltiplas emoções. Não somente impressões físicas são despertadas ao nos aproximarmos dos objetos e documetos ali expostos, mas sobretudo o que mais aproxima este lugar destas pesquisadoras são as interlocuções que podem ser inferidas com os artefatos da cultura escolar e a imersão como historiadoras de tudo o que poderia ser apreendido rompendo o silêncio de tantos sussurros, a partir dos fragmentos de frases e histórias encontradas. Com este sentimento de expectativa e descoberta do passado convidamos o leitor para deslocar-se e unir-se aos encontros e às silhuetas que o presente texto irá oportunizar.

Assim, o estudo inscreve-se no Projeto de Pesquisa "Entre memórias e histórias da escola no RS: Do Deutscher Hilfsverein ao Colégio Farroupilha (1858-2008)", coordenado pela Dra. Maria Helena Camara Bastos e resultante da organização do acervo escolar do Colégio Farroupilha de Porto Alegre/RS/Brasil, que integra pesquisadores - professores, graduandos, mestrandos e doutorandos de diversas instituições. A organização do acervo surgiu da necessidade em preservar a memória da escola e de sua mantenedora, bem como 
promover o encontro entre pesquisa e atividade pedagógica, através da integração dos diferentes agentes das práticas escolares na produção do conhecimento histórico.

Trabalhar com a história das instituições de ensino entendidas como "Escolas", não é tarefa fácil, pois não podemos correr o risco de apenas desenterrar histórias e vultos siginificativos do passado da instituição escolar, como afirmam Nosella e Buffa (2009, p. 30). Mesmo as pessoas sentindo vontade/necessidade de vasculhar o passado, esse conhecimento, segundo os autores, cumpre a finalidade de transcender o imediato, o útil, a banalidade do cotidiano. Este "ir além" cultural é uma necessidade que faz parte da dimensão estética do homem cuja essência é a transcendência do imediatismo (p. 36).

Portanto, estes lugares de memória buscam evitar o esquecimento por meio da construção de laços de identidade. Assim, identidade e memória se tornam componentes essenciais da interação social, e, por isso, não poderiam estar ausentes dos espaços museológicos que pretendam dar conta dos aspectos fundamentais de uma sociedade viva, quer seja no presente ou no passado ${ }^{3}$. Nessa perspectiva, a memória é o conhecimento do passado que se organiza, ordena o tempo, localiza-o cronologicamente, pois lembrar não é apenas reviver, mas refazer, reconstruir com imagens e ideias de hoje as experiências do passado (JACQUES; ALMEIDA, 2014, p. 1-2).

Para chegar inicialmente à concretização de um espaço museológico e de preservação, é necessário destacar que o os museus e, especialmente, o Memorial do Colégio Farroupilha, enquanto espaço de memórias e referências culturais, possibilitam o exercício individual e coletivo do sentimento de pertencimento, visto que através do patrimônio cultural o indivíduo é capaz de reconhecer-se membro de uma coletividade que partilha especificidades e particularidades.

Nesses lugares de memória, segundo Jacques e Almeida, a cultura escolar está presente, permitindo ter acesso ao passado através de vestígios que foram deixados e selecionados, indícios não apagados que representam a vida das instituições escolares e de seus atores sociais. Os escritos ordinários, escritos escolares, imagens, mobiliário, uniformes, memórias orais, entre outros artefatos, considerados patrimônios da educação, contam um pouco da história da instituição, revelam concepções educacionais e geracionais de um determinado tempo e lugar e fazem interlocuções com a história da cidade e do país (2014, p. 2).

Nessa clave, o Colégio Farroupilha ao longo de seus 130 anos sempre esteve

\footnotetext{
${ }^{3}$ Interessante mencionar os três volumes de "Tempos de Escola. Memórias", organizados por Beatriz Daudt Fischer $(2011 ; 2012)$, que professores e pesquisadores narram suas lembranças escolares.
}

Rev. Iberoam. Patrim. Histórico-Educativo, Campinas (SP), v. 2, n. 2, p. 51-72, jan./jun. 2016 
preocupado em preservar a história da instituição ${ }^{4}$. Mesmo mantendo guardado parte do patrimônio histórico escolar em salas ditas "arquivos mortos", este foi fundamental para a constituição do seu Memorial.

No Brasil, a primeira lei de proteção do patrimônio cultural do País, conhecida como Lei do Tombamento (Decreto-Lei n n 25), data de 30/11/1937. No Colégio Farroupilha, a ideia da instituição em preservar seu patrimônio histórico escolar já permeava os registros escritos nas atas do Conselho Escolar, desde a década de 1940. Essa preocupação talvez decorreram das ações governamentais no período do "Estado Novo" e da nacionalização do ensino. Como uma instituição fundada por imigrantes alemães, seus diretores e conselheiros já discutiam as possibilidades de manter viva a história da instituição criando um museu escolar, porém nas atas analisadas não está especificado o tipo de museu que pretendiam formar.

Em nosso país era comum que os museus definissem um público-alvo, assim os mais antigos, alusivos à história nacional, tinham como público cativo e seleto os pesquisadores. Foi justamente na década de 1940, que houve uma preocupação com ações educativas nestes epaços expressas por meio de publicações difundidas pela intelectualidade brasileira que visavam atingir a sociedade de maneira ampla, especialmente os estudantes. Adiante, na década de 1950, a questão da educação nos museus ${ }^{5}$ passa a ser analisada mais profundamente. A aproximação entre museus e escolas deu-se paulatinamente, resultando de uma ação da UNESCO, que incentivou o diálogo entre educadores e técnicos dos museus (KNAUSS, 2011).

Acreditamos que o colégio e sua mantenedora ao longo de todos estes anos, de certa forma se preocupou com a preservação dos seus documentos e artefatos escolares, pois mantinham guardados em salas e armários muitos objetos pertencentes a sua cultura escolar, e que, alguns anos depois foram acolhidos no seu lugar de memória.

Assim, situa-se a criação do Memorial, cuja denominação decorre do nome original da ABE em alemão - Deutscher Hilfsverein (Sociedade Beneficente Alemã). A expressão "Memorial" foi uma escolha do presidente da mantenedora à época - Jorge Guilherme

\footnotetext{
${ }^{4}$ A trajetória do colégio já conta com várias obras publicadas: a do memorialista Leandro Telles (1974), Do Deutscher Hilfsverein ao Colégio Farroupilha 1858/1974; a de Carlos Hofmeiter Filho por ocasião dos 100 anos do colégio (1996); O Caminho das Letras: Os 50 anos de alfabetização da professora Lia Mostradeiro de Dóris Bittencourt Almeida (1999); a obra ABE 150 anos: o passar dos tempos e a educação (2012), coordenado pela historiadora Naida Menezes e o memorialista Leandro Telles e, recentemente as duas obras publicadas pelo Grupo de Pesquisa e organizadas pelas Dras. Maria Helena Camara Bastos, Alice Rigoni Jacques e Dóris Bittencourt Almeida (2013) e (2015).

${ }^{5}$ A Revista do Ensino/RS também atuou neste período apresentando aos professores diversos artigos sobre a importância da criação de museus escolares e museus didáticos nas isntituições de ensino.
} 
Bertschinger -, que entendia que o espaço deveria constituir-se em um "lugar de memória"6, resultado de uma organização planejada, com o objetivo de sacralização da instituição e dos sujeitos que a constituíram e continuam este processo. A Ata $\mathrm{n}^{\circ} 517$ da reunião do Conselho Escolar-Administrativo da ABE, de 10 de junho de 2002, registra a inauguração do Memorial (BASTOS; JACQUES, 2014, p. 54).

Atualmente, alguns livros didáticos de História e Geografia já contemplam e incentivam os professores na criação e organização de museus escolares, destacando procedimentos e metodologias de preservação de acervos ${ }^{7}$. Nas matrizes curriculares há o empenho dos professores em fazer com que seus estudantes passem a analisar documentos (cartas familiares, documentos de hospitais, certidão de nascimento, etc.), observando sua importância e a época em que foram produzidos, bem como analisar documentos produzidos em diversos suportes técnicos e tecnológicos (visuais, textos oficiais e não oficiais, hipertextos, etc.), compreendendo sua importância para a constituição da própria história com o uso da linha de tempo.

Este estudo tem por objetivo discutir a importância do Memorial do Colégio Farroupilha como local de guarda do patrimônio da escola, material e imaterial ${ }^{8}$, como espaço de pesquisa, envolvendo estudantes e professores do colégio e de outras instituições de ensino, especialmente de universidades e, simultaneamente, como espaço educativo e pedagógico. Nessa perspectiva, defendemos que os acervos escolares sejam locais proficientes de trabalho para pesquisadores, professores e estudantes, interessados em entranhar-se na memória local, bem como espaços para estimular diálogos entre a universidade e a escola, e entre esta e a comunidade. Percebe-se a potencialidade do Acervo

\footnotetext{
6 Na acepção de Pierre Nora (1984, p. XXIV), compreende: lugares materiais, em que a memória social se ancora e pode ser apreendida pelos sentidos; lugares funcionais, por que têm ou adquiriram a função de alicerçar memórias coletivas; lugares simbólicos, onde a memória coletiva se expressa e se revela.

${ }^{7}$ Inicialmente é lançado um projeto envolvendo os estudantes, que pode ser intitulado "Nossa escola tem história". A partir do projeto os estudantes são levados a aprender e compreender o que é documento e o que é arquivo. Para auxiliar nesta compreensão, podem ser analisados os arquivos pessoais que compreendem os documentos guardados de cada estudante: certidão de nascimento, título de eleitor, carteira de identidade, álbuns de fotografias, etc. Em seguida analisam-se os documentos da escola: decretos, regimento escolar, cartas, periódicos, fotografias, diários, cadernos, uniformes, etc. Através desta análise, os estudantes encontrarão pistas para compreender a história da escola. Nesse caso, podem organizar um boletim informativo a partir dos dados levantados: fundação da escola, sua relação com a história do bairro e da cidade, as diferentes gerações que ali passaram, o destaque obtido por ex-alunos como profissionais. Também podem relaizar entrevistas a ex-alunos levando os jovens pesquisadores a perceber que todos têm histórias ou um episódio inesquecível a contar a respeito dos seus tempos de estudantes. A organização de um glossário pode introduzir e facilitar a compreensão de alguns termos técnicos da arquivologia. Por fim, a escolha de um local adequado para guardar os documentos, onde eles possam ficar em segurança o maior tempo possível.

${ }^{8}$ Sobre patrimônio imaterial Levi-Staruss (2001) define como uma infinidade de manifestações portadoras de valores profundos da vida de uma população ou de uma comunidade. A literatura oral, os conhecimentos tradicionais, os saberes, os sistemas de valores, as artes de representar e as línguas constituem estas diversas formas de expressão que são as fontes fundamentais da identidade cultural dos povos” (p. 25).
} 
do Colégio Farroupilha pela quantidade e variedade de documentos e artefatos escolares disponíveis para pesquisa e pelo número de produções científicas desenvolvidas em diferentes instituições de ensino superior ${ }^{9}$.

Essa multiplicidade de funções a que se propõe o Memorial implica numa pluralidade de atividades, que incluem, entre outras, localização e seleção de documentos, seu processamento, formas de divulgação e socialização. Pressupõe ainda uma abordagem pluridimensional, capaz de dar conta dos desafios impostos pela totalidade. Assim, o objetivo não é ensinar história, tal qual um manual, sua função está em mostrar o processo histórico que os sujeitos vivenciaram, bem como ensinar a historicidade do mundo em que estamos inseridos. Os sujeitos e os objetos são pontos de partida para trabalharmos a história como problema. Para Ulpiano de Meneses (2011, p. 418): "um museu de história deve ser um museu de problemas e não de coisas históricas”. Essa percepção entende o museu como espaço educativo e de pesquisa, identificando-o como um laboratório de experiências.

Para Jacques e Almeida (2014, p. 3), importa reconhecer a escola como produtora de patrimônios, como "lugar de memória" (NORA, 1993), entendimento este que amplia o conceito de patrimônio para além do que se encontra institucionalizado ou protegido pelas políticas de Tombamento, Registro e Chancela, por exemplo. As experiências coletivas e cotidianas de diferentes grupos questionam a ideia de patrimônio associada ao monumento sacralizado, à memória nacional e aos bens de excepcional valor. Portanto, o museu escolar e suas coleções devem dialogar com diversos tipos de públicos, oportunizando uma experiência que busca a compreensão da história como um processo.

\title{
O MEMORIAL COMO GUARDA DOS PATRIMÔNIOS DA ESCOLA: ESPAÇO MUSEOLÓGICO E DE PRESERVAÇÃO
}

\begin{abstract}
A emoção de entrar no Memorial e ver o que os alunos daquela época usavam de uniforme, como era as classes, é muito grande. Parece que fazemos uma viagem no tempo e nos colocamos no lugar daquelas pessoas. Gostaria que daqui há vários anos os novos alunos do Colégio Farroupilha possam sentir a mesma sensação e também vissem que eu fiz parte da história do Colégio. (GABRIEL WODTKE BOUCHUT, aluno do $3^{\circ}$ A do Ensino Médio, 2002).
\end{abstract}

Adentrar no espaço do Memorial, e se deparar com uma infinidade de objetos de coleções, permite a cada visitante uma viagem no tempo. Nesse sentido, chama atenção o

\footnotetext{
${ }^{9}$ No ano de 2015, o grupo de pesquisa produziu 17 artigos apresentados em simpósios, congressos e encontros regionais, nacionais e internacionais. Uma defesa de tese de doutorado e a publicação do volume II, da obra "Do Deutscher Hilfsverein ao Colégio Farroupilha/RS - Memórias e Histórias (1858-2008)", contemplando 16 artigos realizados.
}

Rev. Iberoam. Patrim. Histórico-Educativo, Campinas (SP), v. 2, n. 2, p. 51-72, jan./jun. 2016 
modo como os sujeitos interajem com os artefatos, por exemplo, quando entrevistas são realizadas por pesquisadores com ex-alunos, e o velho estudante pode ver a maquete da sua antiga escola, fotografias e boletins, entre outros recursos que suscitam lembranças de um tempo que não existe mais, se não na memória e nos vestígios preservados.

Este sentimento de pertença para com a escola não se restringe aos velhos estudantes. Os painéis do ambiente, no qual estão inscritos os nomes dos ex-alunos formados na instituição entre 1920 e 2012, entretém e dão mostras de uma tradição, visto que as crianças fazem deles um grande caça-palavras na busca pelo nome dos pais e avós. Muitas das aulas ministradas no Memorial contam a história da imigração alemã e a trajetória da instituição. Dessa Forma, o "recém-chegado", o aluno, é inserido nesse contexto e passa a se sentir parte dessa história.

O patrimônio cultural, especificamente os objetos de coleção colaboram para que todos sintam-se membros dessa coletividade, percebendo que esses bens the pertencem, têm significados e lembranças, lhes representam enquanto sujeitos desta história, pois fizeram parte de momentos específicos, deixaram suas marcas e percepções, compartilharam experiências, integraram e sentiram-se membros dessa coletividade. Construíram sua própria identidade que, para Guarnieri (1990, p. 41), a identidade cultural está, assim, muito intimamente ligada à vida e à história dos homens, bem como à consciência que eles têm de si mesmos.

Nesse viés de reconstrução de identidades, de marcas e de percepções, o Memorial do Colégio Farroupilha se constituiu. Os primeiros passos para a organização deste lugar de memória se deu pelas professoras, Alice Rigoni Jacques e Adenir Dreher da Silva, em março de 2002, data que começaram a recolha de materiais e o tombamento do arquivo inativo ${ }^{10}$. Os documentos, objetos e materiais escolares foram separados, higienizados e restaurados, partindo para a catalogação, registro e arquivamento. Não começaram do nada, visto que, mesmo nos "arquivos mortos", o colégio já realizava a guarda de alguns objetos e documentos, desde quando a escola era localizada no centro histórico da cidade. Agora, por que guardavam, o que guardavam e como guardavam são perguntas que suscitam curiosidades e indagações. Porém a recolha, separação e identificação das imagens iconográficas iniciaram com a professora Lia Mostardeiro, que após cinquenta anos de sala de aula como alfabetizadora se dedicou à organização do imenso acervo fotográfico, por data, eventos ${ }^{11} \mathrm{e}$

\footnotetext{
${ }^{10}$ Também conhecido como arquivo morto.

${ }^{11} \mathrm{O}$ acervo fotográfico compõe-se em torno de quatro mil imagens, desde as primeiras décadas do século XX. É importante destacar que a escola adota o registro anual das turmas, de alunos individualmente e dos eventos. Um
} 
nome dos estudantes e professores. Segundo Jacques e Almeida (2014, p. 4), muitas vezes, as escolas iniciam a organização de seus acervos intuitivamente, desse modo, se começa a recolher aquilo que estava disperso e organiza-se uma pasta, depois se expande para prateleiras de uma estante, papéis, fotografias, quase por curiosidade.

Nessa ideia de recolher o que estava disperso, foi necessário uma imersão no arquivo morto da escola e nos diversos setores e salas do colégio. Além da separação, seleção e higienização dos documentos e objetos econtrados nestes espaços, foi necessária a realização de visitas a algumas instituições museológicas existentes na cidade de Porto Alegre e na região metropolitana ${ }^{12}$.

Constituído o acervo, foi feita a inscrição do Memorial no Sistema Estadual de Museus/SEM, pertencente à primeira região museológica do Estado do Rio Grande do Sul, e no Sistema Federal (IBRAM ${ }^{13}$ ). Esse procedimento legal insere a instituição anualmente na programação da "Semana Internacional dos Museus", que ocorre no mês de maio. Outra participação oficial se dá no mês de setembro, no evento "Primavera dos Museus", organizada pelo sistema estadual e que neste ano está na décima edição (BASTOS; JACQUES, 2014, p. $55-56)$.

Inicialmente o acervo foi ordenado e organizado a partir de um sistema de registro por letras e números, em cadernos e em pastas com as fichas - de doação e de tombamento. As fichas descrevem o material, facilitando sua localização nos armários e gavetas. As letras correspondem a todos os materiais escritos: revistas, jornais, informativos, relatórios, cartões, relatórios, contratos, atas, cadernos escolares, diários de professores, etc. A numeração de 1 a 1899 correspondem aos demais materiais, como por exemplo: máquinas de gabinetes, material de escritório, máquinas fotográficas, materiais do gabinete médico, instrumentos de laboratórios. Para cada número tem uma gradação em cores para identificação do objeto catalogado. Também foi adotado um caderno de registro de retirada de materiais; agenda de visitas.

Desde a sua criação em 05 de junho de 2002, o espaço físico do Memorial já passou por algumas transformações, as quais evidenciam sua consolidação como espaço de

exemplo é o livro sobre a professora Lia, que incluiu a foto das cinquenta turmas, com o nome de todos os alunos (ALMEIDA, 1999).

12 No museu do Colégio Americano, nos deparamos com diversos objetos de coleção, os quais estavam expostos e identificados contendo aspectos que os caracterizassem, como por exemplo a mobília escolar, os uniformes antigos, a galeria de fotografias dos ex-diretores. No museu do Colégio Sinodal da cidade de São Leopoldo foi nos permitido visualizar as fichas para catalogação dos objetos e documentos, registros de doações e informações sobre reserva técnica. Assim, com estes aspectos observados nas visitas e de forma bastante intuitiva iniciamos a organização do Memorial.

${ }^{13}$ Instituto Brasileiro de Museus. 
preservação, comunicação e pesquisa. Em 2002, ocupava uma sala na entrada da escola, considerando-se a quantidade significativa de documentos que já conservava. Essa sala estava dividida em dois ambientes: um com armários, com o acervo documental e outro para exposições. Quase dez anos depois, em abril de 2011, decorrente da ampliação do acervo e de suas funções, houve o aumento do espaço físico, com mais duas salas. O espaço foi reorganizado estabelecendo uma divisão entre reserva técnica e "espaço expositório", que incluiu também objetos usados na Escola Técnica de Comércio (1950-1973) ${ }^{14}$. Com isso, os objetos e mobiliário escolar foram distribuídos, oportunizando a exposição de uma pequena sala de aula do primeiro ano do curso primário dos anos 1950 (BASTOS; JACQUES, 2014, p. 57-58).

No ano de 2013, decorrente das reformas no prédio administrativo da escola, o Memorial passou a ocupar novas instalações, projetadas especialmente para dar mais visibilidade às suas funções: museológicas, educacionais e de pesquisa. Atualmente, o espaço possui uma área de $90 \mathrm{~m}^{2}$, dividido em três ambientes, por painéis que trazem os nomes dos alunos formandos, desde 1920: um espaço de trabalho, para a coordenação e os pesquisadores, com uma grande mesa, computadores, escâner e armário contendo parte do acervo documental; outro ambiente apresenta uma réplica da sala de aula da década de 1950 e contêm quatro carteiras escolares, mesa da professora, quadro de giz, lousa, bancos escolares, cartilhas, cadernos de alunos, caneta tinteiro, tinta, mata-borrão, estojo de lata para lápis de cor, globo; e, por fim, um espaço destinado ao atendimento das turmas de estudantes. O espaço também contempla armários e outros objetos da cultura escolar (orquestrola, coleção de discos de vinil, harmônio, relógios de parede, materiais pedagógicos e lúdicos que são utilizados nas aulas, almofadas para os alunos sentarem, quadro branco e projetor interativo).

Atualmente, parte do acervo está sendo digitalizado para melhor utilização pelos pesquisadores. Sobre este processo, iniciamos a elaboração de um instrumento de pesquisa, um inventário $^{15}$, que visa contribuir com as especificidades do Memorial do Colégio Farroupilha. Segundo Silva e Petry (2011, p. 21), o inventário incorpora num registro sistematizado materiais pedagógicos, documentos e registros iconográficos, expressões do

\footnotetext{
${ }^{14}$ Sobre, ver Pacheco (2013).

${ }^{15} \mathrm{O}$ inventário realizado contempla os seguintes itens: I -Introdução, II -Mapeamento do Memorial do Colégio Farroupilha, III -Inventário da Documentação quanto ao seu gênero: 1.Acervo Iconográfico (AI): Fotografias, quadros, desenhos, plantas, mapas. 2. Acervo Escrito (AE): Periódicos, atas, relatórios, cadernos, livros, diário de professoras, correspondências, partituras, outros. 3. Acervo Filmográfico (AF): Películas cinematográficas, outros. 4. Acervo Sonoro (AS): Fitas, discos, Cds, outros. 5. Acervo Tecnológico (AT): Documentação administrativa, entrevistas, outros. 6. Acervo material (AM): Exposição permanente, exposição temporária, outros. IV - Política de Acesso e uso dos documentos. O modelo para elaboração deste inventário foi retirado do livro "Arquivo - teorias e práticas" de Marilena L. Paes (1997) e adaptado ao contexto do Memorial.
} 
fazer ordinário da escola, sem esterilizá-los, sem transformá-los em objeto qualquer que sofre os efeitos do registro burocrático, da pura contagem e classificação. A partir do inventário, compreendemos a informação museológica partindo do princípio do objeto como agente de informação e construtor de significados, e do espaço museológico como narrador deste (CASTRO, 1999, p. 13).

A intenção ao realizarmos o inventário do espaço museológico, além de ser um ponto de partida de transformar a informação em conhecimento, também se faz necessário provocar a comunicação, como dispositivo de ativação da informação. De acordo com Silva e Petry (2011, p. 22), o depósito de informação, por mais bem que estruturado e organizado que esteja, não deixa de ser estático e incapaz, isoladamemte, de produzir conhecimento. Portanto, o Memorial deve sempre dialogar com o seu público, e, por isso, a informação deve assumir novo papel no mundo contemporâneo funcionando como vetor de transformação, e o inventário passa a ser uma das estratégias que favorecerão este diálogo entre o acervo e o público.

Ao mesmo tempo em que o Memorial articula-se ao trabalho de mapeamento e registro do acervo existente, outras concepões vão surgindo e se faz necessário conciliar as transições, (re)pensar seu papel, objetivos e ações concretas. Nesse sentido, passa a assumir outras funções: a de espaço de aprendizagem e de pesquisa.

\title{
O MEMORIAL COMO ESPAÇO EDUCATIVO E PEDAGÓGICO
}

\begin{abstract}
La educación en el museo es un elemento demasiado importante como para dejar-la sólo em manos de los responsables del área educativa. Tiene que impregnar a todos los que trabajan allí [...] la política del museo debe ser una política educativa [...] la educación es el componente clave en la raison d'être de los museos (PITTMAN, 1991 apud HOOPER-GREENHIL, 1998, p. 25).
\end{abstract}

Desde a sua criação, o Memorial vem se constituindo cada vez mais também como um espaço educativo pedagógico, expandindo-se das coleções ao fator humano nas instituições museológicas e demonstrando, por meio das diversas situações promovidas, o caráter educacional em suas atividades.

Para organizar, dinamizar e qualificar o caráter educativo inerente à função pedagógica, é de suma importância a adoção de uma política educacional conectada ao projeto político pedagógico da escola e que oriente o desenvolvimento de um planejamento detalhado amparado nas matrizes curriculares. Por acreditarmos que os museus devem estar em constante movimento, é extremamente relevante maximizar a função educativa de seus 
acervos e atividades. Para Figurelli (2011, p. 118), estender as atuações da educação para os outros segmentos, suscitando debates, reflexões, alterações, renovações entre os colaboradores, promovendo melhorias nas atividades desenvolvidas e no desempenho da equipe, compreendendo a contribuição para o desenvolvimento do fazer museológico, é perceber o museu como um espaço - genuinamente - educativo.

Ao expandirmos a ideia de espaço pedagógico, o Memorial privilegia a aprendizagem por meio de oficinas e aulas temáticas contribuindo para a função educativa pautada em relações e interações com o público. Segundo Figurelli (2011, p. 119), o acesso a uma formação voltada para o contato com os espaços museológicos, estimula os estudantes a olhar criticamente, a ler os objetos e os espaços, a identificar as mensagens subentendidas, a perceber o discurso oculto na expografia, a criar novos significados, relações e narrativas.

Muito além da visita guiada à exposição, a ação educativa precisa privilegiar a
preparação para as "leituras da exposição", direcionando suas iniciativas para a
formação integral do ser humano. Assim, a ação educativa em museus, utilizando-se
de textos, atividades, visitas, palestras, etc., deve ser capaz de potencializar a
construção de conhecimentos do público em sua multiplicidade, desenvolvendo um
olhar curioso e investigativo no contato com a instituição e os objetos ali
resguardados, visando ampliar sua capacidade crítica. (CHIOVATTO; AIDAR,
2007).

Nesse viés de proporcionar diferentes leituras em relação aos espaços museológicos, o Memorial, por meio da realização de oficinas, aproxima os estudantes e professores das diversas disciplinas do currículo, da Educação Infantil ao final do Ensino Médio.

Além das disciplinas de História, Geografia e Estudos Sociais, a área da Matemática também é contemplada nas atividades pedagógicas. A oficina intitulada "Do detalhe à forma: o Colégio Geométrico", tem como objetivo promover um estudo interdisciplinar a partir da análise das formas geométricas das edificações do Colégio Farroupilha presentes em fotografias antigas e atuais, com vistas a perceber o processo de transformação da arquitetura da cidade, ou seja, como o Colégio se insere nesse processo e como se desenvolve a patrimonialização dos edifícios. Em termos práticos, os estudantes (dos anos iniciais) recebem duas fotografias do colégio, uma antiga e uma atual, com o papel vegetal traçam à lápis as formas geométricas encontradas nas imagens, posteriormente apresentam o resultado aos colegas. 
Figura 1, 2 e 3: Oficina "Do Detalhe a Forma".

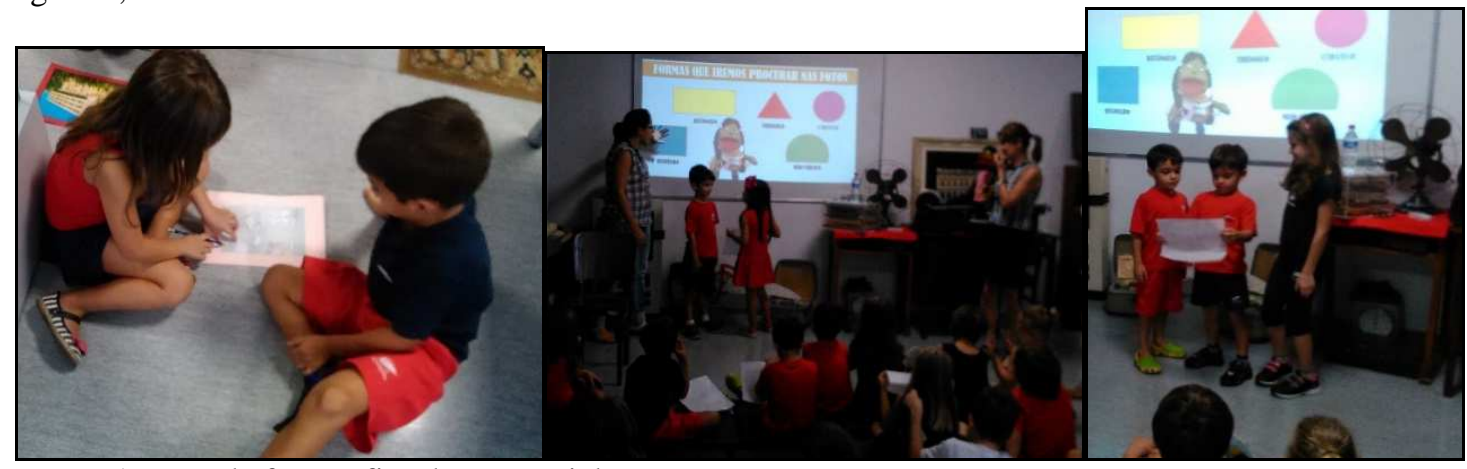

Fonte: Acervo de fotografias do Memorial.

Outra oficina desenvolvida para os estudantes do ensino fundamental anos finais e ensino médio, versa sobre as mudanças tecnológicas ocorridas no colégio, da década de 1920 a 2010. A partir de imagens e da exposição de artefatos escolares pertencentes ao acervo, permite os estudantes perceber as mudanças ocorridas que vão desde a caneta tinteiro até o uso dos tablets. Após são convidados a interagir nos IPADS, por meio do aplicativo Nearpod $^{16}$, a preencher o quadro seguinte:

Quadro 1: Ficha de atividade: Oficina "Da caneta tinteiro aos tablets".

\begin{tabular}{|c|c|}
\hline \multicolumn{2}{|c|}{$\begin{array}{l}\text { Análise de um objeto/artefato/documento do Memorial Do Deutscher Hilfsverein ao } \\
\text { Colégio Farroupilha }\end{array}$} \\
\hline Objeto/artefato/documento & \\
\hline Descrição da materialidade & \\
\hline Função & \\
\hline $\begin{array}{l}\text { Período/temporalidade } \\
\text { aproximada }\end{array}$ & \\
\hline $\begin{array}{l}\text { O que se pode analisar } \\
\text { sobre a história/usos do } \\
\text { objeto }\end{array}$ & \\
\hline $\begin{array}{l}\text { Desafio } \\
\text { "Inventores da } \\
\text { Contemporaneidade" } \\
\text { A partir do objeto/artefato } \\
\text { escolhido para descrição, } \\
\text { criar novos usos que visem } \\
\text { facilitar a vida das pessoas } \\
\text { no mundo de hoje. }\end{array}$ & \\
\hline
\end{tabular}

Fonte: Memorial do Colégio Farroupilha.

${ }^{16}$ Nearpod é um aplicativo de sala de aula para os professores desenvolverem aulas interativas com seus alunos utilizando Ipads, Ipods, Iphones, etc. 
Figuras 4 e 5: Exposição "Da caneta tinteiro aos tablets".

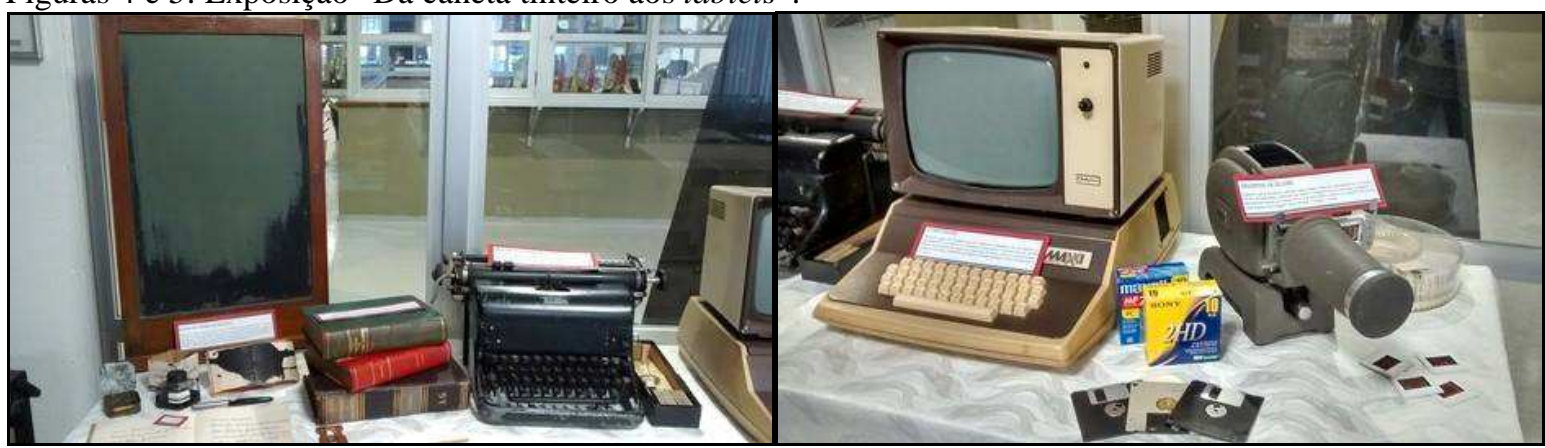

Fonte: Memorial do Colégio Farroupilha.

Nesta atividade, os estudantes são levados a identificar o papel dos meios de comunicação na construção da vida social, interpretar historicamente e/ou geograficamente fontes documentais acerca de aspectos da cultura, bem como analisar a produção da memória pelas sociedades humanas.

Embora ainda se fragmente os saberes através de currículos escolares, numa sociedade globalizada mesmo de forma contraditória, o patrimônio cultural pode ser visto como um contributo para estimular a capacidade de estabelecer relações e criar diálogos. Segundo Horta, Gurnberg e Monteiro (1999), a habilidade de interpretar objetos e fenômenos culturais expande a capacidade de compreender o mundo. Portanto, bens culturais podem colaborar para a formação do indivíduo antenado com as exigências do seu tempo, que requer pessoas criativas e imaginativas, capazes de observar, analisar, interpretar, contextualizar e ressignificar dados, fatos, tempos e espaços.

Também o estudo com imagens, além de ser um dispositivo de informação e formação oferece múltiplas possibilidades de leitura e não apenas serve como elemento ilustrativo dos textos. Assim, a utilização de fotografias como fonte de pesquisa e documento histórico tem se configurado como importante instrumento no processo de constituição da história de lugares e de pessoas. A oficina desenvolvida para os anos finais do ensino fundamental, intitulada "Retratos do tempo de escola: a pesquisa com fotografias antigas", oportuniza aos estudantes trabalhar com a memória fotográfica do colégio, no sentido de divulgar e promover as origens da instituição e a produção de conhecimentos a respeito da mesma; além disso, propicia aos estudantes oportunidades de diálogo, rememoração e reflexão com imagens, através da constituição de grupos e equipes de trabalho.

A dinâmica da oficina ocorre da seguinte forma: inicia com a contação da história do colégio, a partir de imagens pertencentes ao acervo, formação de grupos de estudantes, distribuição de envelopes contendo fotografias de acordo com as categorias selecionadas 
(turma de alunos, festas escolares, salas de aula, formaturas, pátio do colégio, grupo de professores, etc.), análise das imagens seguida de discussão no grupo, preenchimento do quadro 2, a partir da análise realizada e das perguntas propostas, e, por último, a apresentação coletiva das conclusões do grupo.

Quadro 2: Ficha da oficina: Retratos do tempo de escola: a pesquisa com fotografias antigas.

\begin{tabular}{|l|l|}
\hline \multicolumn{2}{|l|}{ Grupo: } \\
\hline Data da fotografia ou estimativa do período & \\
\hline Local & \\
\hline Pessoas & \\
\hline Cenário & \\
\hline Estúdio/fotógrafo & \\
\hline Quem é o guardador? & \\
\hline $\begin{array}{l}\text { Quais as práticas registradas na fotografia } \\
\text { que ajudam no entendimento do presente? }\end{array}$ & \\
\hline Que elementos nos remetem ao passado? & \\
\hline $\begin{array}{l}\text { Quais conhecimentos são vistos e } \\
\text { percebidos nas imagens? }\end{array}$ & $\begin{array}{l}\text { Hábitos: } \\
\text { Vestimenta: } \\
\text { Personagens: } \\
\end{array} \quad \begin{array}{l}\text { Ocupação humana: } \\
\text { Educação ambiental: } \\
\text { Economia: }\end{array}$ \\
\hline
\end{tabular}

Fonte: Memorial do Colégio Farroupilha.

A atividade descrita acima mostra a fotografia como fonte de pesquisa, permitindo trabalhar a imagem como doumento histórico. É uma oportunidade que se apresenta aos estudantes de acrescentar novas e diferentes interpretações da história, conhecer os atores sociais e os cenários cotidianos e, sobretudo, expressar realidades vividas em outros tempos. Portanto, ao inserir a fotografia nas atividades escolares estamos procurando mostrar aos estudantes, o que Mauad (2005, p. 143) destaca, que as fotografias guardam, na sua superfície sensível, a marca indefectível do passado que as produziu e consumiu. Um dia já foram memória presente, próxima àqueles que as possuíam, as guardavam e colecionavam como relíquias, lembranças ou testemunhos. No processo de constante vir a ser, recupera o seu caráter de presença num novo lugar, num outro contexto e com uma função diferente.

Enfim, são diversas oficinas e aulas temáticas desenvolvidas no Memorial que desde a sua fundação estiveram presentes neste espaço de memória. Nos últimos três anos (2013, 2014 e 2015), o Memorial já oportunizou 24 temas para a realização das oficinas e aulas temáticas, recebeu 4024 estudantes e 144 professores. 
Além destas atividades, o Memorial realiza simultaneamente exposições temáticas. Atualmente está promovendo a exposição "Da caneta tinteiro aos tablets: os recursos didáticos entre as décadas de 1950 a 2010”, em parceria com o setor de tecnologia educacional da escola. Por ocasião do aniversário do colégio, realizou no mês de março deste ano, as exposições "130 anos de História do Colégio Farroupilha”; "À sombra das Três Figueiras: imagens de uma nova Escola (1928-1962)", em que apresentou um recorte dos 51 anos do Colégio Farroupilha no Bairro Três Figueiras, contextualizando os diversos significados que a chácara da Vila Quinota teve até tornar-se Bairro Três Figueiras. Em parceria com a professora que ministra a oficina Afro-Indígena aos estudantes dos anos iniciais, realizou a exposição sobre a Consciência Negra mostrando a cultura e os costumes Afro-Brasileiros.

Como vimos, o Memorial desenvolve uma ação educativa permanente, dinâmica e sistemática. Essa ação vai de encontro ao que Figurelli (2011, p. 128) destaca, ao pensar o museu enquanto processo educativo é necessário identificar as possibilidades de aprendizagem presentes nas tarefas cotidianas da instituição, colaborando com a sociedade na qual está inserido. Segundo a autora, é preciso compreender que os museus possuem potencial para oferecer oportunidades educacionais para todos os públicos. É preciso identificar o caráter educativo presente na ação de preservação, comunicação e de pesquisa. Sobre este último item é o que trataremos a seguir.

\section{APROXIMAÇÕES E POSSIBILIDADES DE PESQUISA NO ESPAÇO DO MEMORIAL}

[...] os museus a partir das suas funções, constata-se que são instituições estreitamente ligadas à informação de que são portadores os objetos e espécimes de suas coleções. Estes, como veículo de informação, têm na conservação e na documentação as bases para se transformar em fontes para a pesquisa científica e para a comunicação que, por sua vez, geram e disseminam novas informações (FERREZ, 1994, p. 65).

Como espaço de coleção e de aprendizagem, os museus têm sido lugares profícuos para quem elege a História da Educação como campo de ensino e pesquisa. Durante esses anos, o grupo realizou várias pesquisas e vem refletindo acerca de diferentes aspectos dessa instituição de ensino. Também analisa a(s) cultura(s) ou o(s) elementos desse espaço educativo e escolar, descrevendo e problematizando seus atores, os aspectos organizativos e 
institucionais, as práticas pedagógicas, o entorno físico-material ${ }^{17}$. Ou seja, tudo aquilo que contribui para caracterizar a escola como instituição histórica.

Em 2013, publicamos a primeira coletânea de estudos do Grupo de Pesquisa. E, no ano de 2015, ao celebrar o centésimo vigésimo nono aniversário do Colégio Farroupilha e o décimo terceiro ano do Memorial, publicamos o segundo volume que reúne uma série de estudos sobre a história da escola, apresentando investigações sobre diversas perspectivas, relatando e indagando os domentos/monumentos ${ }^{18}$ acerca dos elementos que os revestem: atores, discursos, aspectos organizativos e institucionais, entorno físico-material, currículo, disciplinas, educação feminina e educação masculina.

Além das duas obras publicadas, o grupo vem participando de diversos eventos, congressos e simpósios regionais, nacionais e internacionais cujo tema discursa sobre a História da Educação, caracterizando o Colégio Farroupilha como instituição historicamente construída.

Outra ação educativa, é realizada em parceria com as universidades, com estudantes de Pedagogia, História, Matemática e demais licenciaturas, no qual elege-se o Memorial como lócus de investigação. Inicialmente promove-se uma visita ao Memorial para que os estudantes possam experimentar, instigar e problematizar o espaço. De forma metodológica, escolhem um documento explicando sua materialidade, periodização, relação com a educação. Em seguida, produzem um texto escrito, acerca dos possíveis significados da visita. Promovese também uma discussão sobre que políticas públicas deveriam ser implementadas para que outras instituições pudessem ter suas memórias salvaguardadas. Esta atividade além de oportunizar discussões acerca do conceito de memória, introduzir outros conceitos como cultura e patrimônio escolar, acervos institucionais, o sentido de documento para a História da Educação, o que significam documentos oficiais e ordinários, quais suas características e usos para a pesquisa acadêmica, também procura apresentar o Memorial como espaço de coleção e pesquisa, articulado com a disciplina desenvolvida.

\footnotetext{
${ }^{17}$ O Velho Casarão foi a primeira sede própria do Colégio Farroupilha, inaugurada em 1895. Localizava-se na antiga Rua São Raphael, atual Av. Alberto Bins, centro histórico de Porto Alegre. Funcionou neste local até 1962, quando foi transferido para o Bairro Três Figueiras. O edifício foi demolido e hoje o espaço é ocupado pelo Hotel Plaza São Rafael. Os estudos feitos sobre esse espaço e arquitetura escolar dependem atualmente os acervos fotográficos, plantas, croquis, entre outros documentos pertencentes ao Memorial. Para mais informações sobre a antiga sede, ver Jacques e Ermel (2013).

${ }^{18}$ A memória coletiva e a sua forma científica, a história, aplicam-se a dois tipos de materiais: os documentos e os monumentos. De fato, o que sobrevive não é o conjunto daquilo que existiu no passado, mas uma escolha efetuada quer pelas forças que operam no desenvolvimento temporal do mundo e da humanidade, quer pelos que se dedicam à ciência do passado e do tempo que passa, os historiadores. Estes materiais da memória podem apresentar-se sob duas formas principais: os monumentos, herança do passado, e os documentos, escolha do historiador (LE GOFF, 1990, p. 535).
} 
A pesquisa histórica é um dos caminhos para que o museu possa contribuir, efetivamente para o desenvolvimento sócio-cultural. Sendo assim, nenhum pesquisador pode tratar seu objeto de pesquisa como coisa inerte. Desse modo, o acervo do Memorial além de oportunizar o acesso aos estudantes da cidade de Porto Alegre/RS, também tem proporcionado ao longo deste tempo, para que várias universidades usufruam do acervo, entre eles citamos os estudantes das licenciaturas de Matemática da Universidade Federal de São Paulo (UNIFEST), no qual pesquisaram as práticas educativas da Aritmética e da Geometria em cadernos escolares, da Universidade Federal de Pelotas (UFPel) que se interessaram em conhecer a constituição e organização do espaço museológico, da Universidade do Vale do Rio dos Sinos (Unisinos) que pesquisou sobre as práticas educativas desenvolvidas nas aulas de Ciências Naturais e do curso de Pós-Graduação em Educação da PUC do Paraná que também investigava sobre o desenvolvimento da Matemática nas décadas de 1920 a 1950.

Múltiplas atividades são desenvolvidas no Memorial que, ao longo de seus 14 anos, ampliou suas finalidades. Com o objetivo de apresentar a história do colégio e de sua mantenedora, a Central de Matrículas da escola oportuniza aos pais uma visita guiada a este espaço. Esta atividade, também é proporcionado aos novos professores e colaboradores oportunizando a inserção na história. Nos encontros anuais de turmas de ex-alunos, a ida ao memorial faz parte da programação, o que tem estimulado a doação de materiais e o registro de depoimentos do seu tempo de escola.

Atualmente o Memorial tem se preocupado em ampliar o seu acervo, a partir da realização de entrevistas com ex-professores, ex-alunos sobre sua trajetória e experiências escolares. Desse modo, nos desafiamos a constituir um acervo de Fontes Orais o que irá permitir reconstruir fragmentos da instituição, a partir do registro da vida dos professores, diretores estudantes, [e de suas memórias], de suas maneiras de ser e ensinar.

\section{CONSIDERAÇÕES FINAIS}

Toda operação científica ou pedagógica sobre o patrimônio é uma metalinguagem, não faz falar das coisas, mas fala de e sobre elas. [...] O museu e qualquer política patrimonial devem tratar os objetos, os ofícios e os costumes de tal modo que, mais que exibi-los tornem inteligíveis as relações entre eles, proponham hipóteses sobre o que significam para a gente que hoje os vê e evoca (CANCLINI, 1994, p. 113).

Compreender as ações educativas nos museus e, neste caso, no Memorial do Colégio Farroupilha significa ir além da concepção ingênua que se debruça sob os artefatos de maneira saudosista e simplória, na qual, muitas vezes, as coleções são dispostas apenas à 
contemplação, seguidas de pequenas notas explicativas a respeito da materialidade do objeto. O interesse em atrelar a documentação às atividades educativas está no reconhecimento destes elementos como um importante instrumento da aprendizagem, visto que a materialidade escolar nos provoca questionamentos que impulsionam a construção histórica.

A discussão que incorpora a fala dos ex-alunos, alunos, pesquisadores e documentos permite que sejam criadas correntes de pensamento, que resultam na valorização do patrimônio histórico-educativo. A preservação do mesmo está sujeita ao entendimento de que estes artefatos são relevantes para a constituição da história do educandário e da Educação brasileira.

A maneira como o Memorial é lido e interpretado relaciona-se com as experiências, objetivos e interesses dos indivíduos que a ele se dirigem. Assim, a consolidação da sociedade escolar baseia-se na construção de uma memória, história e identidade compartilhada. $\mathrm{O}$ espaço museológico do Memorial do Colégio Farroupilha, pode compreender um universo que, ao mesmo tempo, se mostra familiar e distante. As peças das coleções são vestígios e representações de outras épocas, amostras de um passado, muitas vezes não vivido pelo sujeito que o observa, mas compreendido por seus precedentes, pela sua comunidade, pelos estudantes que lá estavam antes daquele que hoje ali estuda. Dessa forma, a materialidade é revestida de representações simbólicas, de ideias e imagens. A política de conservação é despertada a partir da interlocução com os grupos e a pesquisa.

As investigações, que trazem à tona a relação da cultura material com o cotidiano escolar, encontram no Memorial um ambiente favorável à pesquisa, tendo em vista as diferentes possibilidades de investigação que viabiliza. Para Bastos e Jacques (2014, p. 72), o permanente diálogo do pesquisador (e de suas teorias) com as fontes resulta na produção do conhecimento científico. Assim, os objetos e documentos que dormiam já não mais estão sós. Aos poucos, eles foram sendo despertados e ressignificados, voltando a viver a partir de novos sujeitos.

As investigações realizadas no Memorial procuram produzir narrativas que atendam desde os estudantes dos anos iniciais até a universidade, compreendendo que o mesmo só tem significado à medida que se conecta com a sociedade. Zancul (2015, p. 119), afirma que a valorização do patrimônio histórico-educativo está ligada ao conhecer, entender e divulgar a importância cultural e social da instituição escolar. Atualmente, a comunicação, entre a comunidade escolar e acadêmica, acerca das atividades desenvolvidas no espaço do 
Memorial, além das visitas realizadas também coloca à disposição os recursos midiáticos alternativos como as redes sociais.

Assim, fertilizar o debate sobre as potencialidades do patrimônio histórico-escolar, tendo como objeto o Memorial do Colégio Farroupilha, é ir além do espaço físico de contemplação, pois por meio das redes sociais estamos conectados e interagindo, em grande parte com o que é promovido e desenvolvido com e para a comunidade a qual pertence.

A relação que o museu estabelece com a sociedade e o patrimônio, considerado como instituição histórico-social, não pode ser visto como um produto pronto, acabado; ele é o resultado das ações dos sujeitos que o estão construindo e reconstruindo, a cada dia. Para Santos (2001, p. 11), são as nossas concepções de museologia e de museu que estarão atribuindo à instituição diferentes perfis, que deverão ser adaptados aos diversos contextos.

O processo de constituição do Memorial resulta da conscientização do público e dos dirigentes da escola em manter e aprimorar este lugar de memória. Com isso, a documentação sofreu um processo de recuperação, higienização, guarda, e inventariação que contribuiu efetivamente para o desenvolvimento de diversas análises no campo da História da Educação, em suas interfaces com outras áreas do conhecimento.

O trabalho desenvolvido no Memorial não se encerra nestes feitos. Os projetos que estão em processo são o resultado de um planejamento que vislumbra novos horizontes, como por exemplo, o desenvolvimento de um acervo de fontes orais, a digitalização do acervo fotográfico e de um catálogo on-line, que permita realizar consultas à documentação. Há uma preocupação em continuarmos com as propostas que caracterizaram nossas ações iniciais, mas também há um desassosego que nos instiga a "pensarmos fora da caixa". As práticas realizadas no Memorial, ainda que se detenham sobre objetos do passado adquirem uma prerrogativa contemporânea, assim se engana quem diz que "quem vive de passado é o Museu".

\section{REFERÊNCIAS}

ALMEIDA, Dóris B. O Caminho das Letras: os cinquenta anos de alfabetização de Lia Mostardeiro. Porto Alegre: Ed. ABE, 1999.

BASTOS, Maria Helena Camara; JACQUES, Alice Rigoni; ALMEIDA, Dóris Bittencourt (Org.). Do Deutscher Hilfsverein ao Colégio Farroupilha/RS: Memórias e histórias (1858 2008). Porto Alegre: EDIPUCRS, 2013. 
Memórias e histórias (1858 - 2008). Porto Alegre: EDIPUCRS, v. 2, 2015.

; _ Liturgia da memória escolar: Memorial Do Deutscher Hilfsverein ao Colégio Farroupilha 2002. Revista Linhas, Florianópolis, v. 15, n. 28, p. 49-76, jan/jun 2014.

CANCLINI, Néstor García. O patrimônio cultural e a construção imaginária do nacional. Revista do Patrimônio Histórico e Artístico Nacional, Rio de Janeiro, Iphan, n. 23, p. 95115, 1994.

CASTRO, Ana Lucia Siaines de. Informação museológica: uma proposição teórica a partir da Ciência da Informação. In: PINHEIRO, Lena Vania Ribeiro (Org.). Ciência da Informação, ciências sociais e interdisciplinaridade. Brasília; Rio de janeiro: IBICT, 1999, p.13-31.

CHIOVATTO, Milene; ADAIR, Gabriela. Ação educativa em museus. In: PARK, Margareth; FERNANDES, Renata; CARNICEL, Amarildo. (Orgs.). Palavras-chave em educação nãoformal. Holambra/Campinas: setembro/Unicamp-CMU, 2007.

FARGE, Arlette. O sabor do arquivo. São Paulo: Editora da Universidade de São Paulo, 2009.

FERREZ, H. D. Documentação museológica: teoria para uma boa prática. Cadernos e ensaios, n. 2, Rio de Janeiro, Minc/Iphan, p. 64-73, 1994.

FIGURELLI, Gabriela Ramos. Articulações entre educação e museologia e suas contribuições para o desenvolvimento do ser humano. Revista Eletrônica do Programa de PósGraduação em Museologia e Ptrimônio - PPG-PMUS Unírio/MAST - vol.4 n.2, 2011.

FISCHER, Beatriz Daudt (Org.) Tempos de escola. Memórias. São Leopoldo: Oikos; Brasília: Liber livro, 2011. (V. 1 e v. 2)

(Org.) Tempos de escola. Memórias. São Leopoldo: Oikos; Brasília: Liber livro, 2012. (V. 3)

GUARNIERI, Waldisa. O conceito de cultura e sua inter-relação com o patrimônio cultural e a preservação. Cadernos museológicos, Rio de janeiro: IBPC, n.3, 1990, p. 7-12.

HOFMEISTER FILHO, Carlos. 1886-1996 Colégio Farroupilha: 100 anos de pioneirismo. Porto Alegre: Palotti, 1996.

HOOPER-GREENHILL, Eilean. Los museos y sus visitantes. Gijón: ediciones TREA, 1998.

HORTA, Maria de Lourdes; GRUNBERG, Evelina; MONTEIRO, Adriane. Guia básico de educação patrimonial. Brasília: IPHAN/Museu Imperial, 1999.

KNAUSS, Paulo. A presença de estudantes: o encontro de museus e escola no Brasil a partir da década de 50 do século XX. Revista Varia História, Belo Horizonte, v. 27, n. 46, 2011. Disponível em: <http://www.scielo.br/scielo.php?pid=S010487752011000200010\&script=sci_arttext\&tlng=es >. Acesso em: 10 mar. 2016. 
JACQUES, Alice Rigoni; ERMEL, Tatiane de Freitas. O velho casarão, um estudo sobre o Knabeschule des Deutsches Hilfsverein/Colégio Farroupilha (1895-1965). In: BASTOS, Maria Helena Camara; JACQUES, Alice Rigoni; ALMEIDA, Dóris Bittencourt (Org.). Do Deutscher Hilfsverein ao Colégio Farroupilha/RS: Memórias e histórias (1858 - 2008). Porto Alegre: EDIPUCRS, 2013, p. 92-110.

JACQUES, Alice Rigoni; BITTENCOURT, Dóris Almeida. Acervo Escolar do Colégio Farroupilha: lugar de ensino e de pesquisa. XI CONGRESO IBEROAMERICANO DE HISTORIA DE LA EDUCACIÓN LATINOAMERICANA. México, 2014.

LE GOFF, Jacques. História e Memória. Campinas/SP: Editora UNICAMP, 1990.

LÉVI-STRAUSS, L. Patrimônio Imaterial e Diversidade Cultural: o novo decreto para a proteção dos bens imateriais. Revista tempo brasileiro, n. 147, p. 23-44, out.-dez. 2001.

MAUAD, Ana Maria. Na mira do olhar: um exercício de análise da fotografia nas revistas ilustradas cariocas, na primeira metade do século XX. Anais do Museu Paulista, n. 1, p. 133$174,2005$.

MENESES, Ulpiano Toledo Bezerra de. Entrevista. 31 mar. 2011. Entrevistadoras: Luciana Quillet Heymann e Aline Lopes de Lacerda. Revista Estudos Históricos, Rio de Janeiro, v. 24, n. 48, p. 405-41, dez. 2011.

NORA, Pierre. Entre mémoire et histoire: la problématique des lieux. In: NORA, Pierre (Org.). Les lieux de mémoire. Paris: Gallimard, [1984]; La République, v. 1 p.

. Entre memória e história: a problemática dos lugares. Projeto História. São Paulo: PUC-SP, n. 10, p. 12, 1993.

NOSELLA, Paulo; BUFFA, Ester. Instituições escolares: por que ecomo pesquisar. Campina, SP: Alínea, 2009.

PACHECO, Pietro Gabriel dos Santos. A Escola Técnica de Comércio Farroupilha (ETC/1949-1982). In: BASTOS, Maria Helena Camara; JACQUES, Alice Rigoni; ALMEIDA, Dóris Bittencourt (Org.). Do Deutscher Hilfsverein ao Colégio Farroupilha/RS: Memórias e histórias (1858 - 2008). Porto Alegre: EDIPUCRS, 2013, p. 260-282.

PAES, Marilena Leite. Arquivo - Teorias e Párticas. Rio de Janeiro: Editora FGV, 1997.

SANTOS, Maria Célia T. Moura. Museu e Educação: conceitos e métodos. Simpósio Internacional Museu e Educação: conceitos e métodos, agosto 2001.

SILVA, Vera Lúcia Gaspar da; PETRY, Marília Gabriela. A aventura de inventariar: uma experiência no Museu da Escola Catarinense. Revista Brasileira História da Educação, Campinas-SP, v. 11, n. 1 (25), p. 19-41, jan./abr. 2011.

TELLES, Leandro. Do Deutscher Hilfsverein ao Colégio Farroupilha 1858/1974. Porto Alegre: ABE, 1974. 
MENEZES, Naida. O passar dos tempos e a educação: a excelência na história do Colégio Farroupilha. Porto Alegre, 2012.

ZANCUL, Maria Cristina de Senzi. Patrimônio educativo e patrimônio histórico-científico no Brasil: alguns apontamentos. Museologia e Patrimônio - Unirio - MAST, v. 8, n. 2, p. 104122,2015 , 